\title{
О.А. Крапивкина
}

\section{ОПЫТ АНАЛИЗА ДИСКУРСИВНЫХ ПРАКТИК КАК ФОРМ СОЦИАЛЬНОГО ВЗАИМОДЕЙСТВИЯ (НА МАТЕРИАЛЕ СУДЕБНЫХ ТЕЛЕШОУ)}

\begin{abstract}
В статье представлен взгляд на дискурс как инструмент сочиального взаимодействия. Цель исследования заключается в анализе форм сочиального взаимодействия в рамках юридических дискурсивных практик и установлении их зависимости от уровня владения участником коммуникации экспертным знанием. Новизна работы заключается в изучении юридических дискурсивных практик в их связи с семиотическими сущностями - концептом, понятием и термином. Форма социального взаимодействия коррелирует с семиотической сущностью, вокруг которой организуется дискурс. Материалом для анализа послужили судебные шоу, транслируемые на федеральных телеканалах, в которых рассматриваются вымышленные гражданские и уголовные дела с участием реальных юристов. Теоретической базой исследования послужила концепция эволюции форм знания А.М. Каплуненко.

Ключевые слова: дискурс, юридический дискурс, социальное взаимодействие, экспертное сообщество, термин, понятие.
\end{abstract}

Проблемы социального взаимодействия, основой которого выступают дискурсивные практики, всегда находились в центре внимания исследователей. Значительный вклад в развитие теории социального действия и социального взаимодействия внесли социологи М. Вебер, П. Сорокин, Дж. Хоманс, Т. Парсонс и др. Совершая какое-либо социальное действие, субъект оказывает воздействие на поведение другого, от которого получает ответное действие - «воздействие». Социальное взаимодействие - это система взаимообусловленных социальных действий, при которой действие одного субъекта является одновременно причиной и следствием ответных действий других субъектов, это процесс непосредственного или опосредованного взаимодействия социальных субъектов [1]. Для социального взаимодействия характерны предсказуемость взаимных ожиданий, взаимопонимание между субъектами. Если субъекты «говорят на разных языках» и преследуют взаимоисключающие цели и интересы, то результаты такого взаимодействия вряд ли будут положительными, а коммуникативный эффект может быть «сведен к нулю».

Социальная интеракция невозможна вне дискурсивных практик, включающих производство и восприятие текстов [2. С. 110]. Любой вид взаимодействия между индивидами и социальными образованиями предполагает осуществление коммуникативных актов, проявляется в дискурсах, которые выступают в качестве инструментов социального взаимодействия. Дискурс, реализуясь в качестве социально упорядоченных, регламентированных коммуникативных актов и выражаясь в текстах определенного типа, является 
уникальным орудием для осуществления и развития социального взаимодействия в обществе [3. С. 255].

В рамках настоящего исследования релевантным является определение дискурса, предложенное Е.И. Шейгал, которая описала его как семиотическое пространство, включающее вербальные и невербальные знаки, ориентированные на обслуживание данной коммуникативной сферы, представление о типичных моделях речевого поведения и набор речевых действий и жанров, специфичных для данного типа коммуникации» [4. С. 11]. Оказываясь в определенной коммуникативной ситуации, коммуникант оценивает ее и выбирает соответствующее ей речевое действие, следуя правилам, выработанным в дискурсивном сообществе. Наличие правил является предпосылкой социальной интеракции.

Таким образом, социальное взаимодействие может иметь различный характер в зависимости от коммуникативной ситуации, целей коммуникации, характеристик коммуникантов [5. С. 23].

Материалом для исследования послужили судебные шоу, транслируемые на федеральных телеканалах НТВ, Россия 1 и Первый: Час суда, Федеральный судья, Суд присяжных, Суд присяжных: окончательный вердикт. Было подвергнуто анализу около 70 выпусков данных программ. В статье приведены примеры из двух телешоу: Суд присяжных и Час суда.

Судебные шоу представляют собой телевизионные программы, в которых рассматриваются вымышленные уголовные и гражданские дела с участием реальных юристов в роли судей, адвокатов и прокуроров. Все участвующие в шоу юристы в действительности являются адвокатами. Это связано с положением законодательства, согласно которому действующие судьи и прокуроры не имеют права заниматься какой-либо другой профессиональной деятельностью, кроме юридической и преподавательской.

В судебном шоу «Суд присяжных» рассматриваются тяжкие уголовные преступления: убийства, похищения людей, ограбления, изнасилования, разбои, в юридическом шоу «Час суда» только гражданские дела без участия адвокатов.

Реальность основных участников, знакомых с особенностями правовой коммуникации и владеющих экспертным знанием, позволила нам условно идентифицировать данные телешоу и реальные юридические дискурсивные практики, разворачивающиеся в ходе судебных заседаний.

Опираясь на теорию эволюции форм знания, предложенную А.М. Каплуненко [6, 7], рассмотрим три формы социального взаимодействия в рамках юридической коммуникации на материале судебных шоу: Дискурс Различий - речевая деятельность, в которой преобладает феноменологическое знание, опирающееся на индивидуальный опыт, а не на экспертное знание; Дискурс Согласования - речевая деятельность, участники которой стремятся к утверждению общей точки зрения, организующаяся вокруг понятия, к которому коммуниканты приходят в результате конвенции, сотрудничества; Дискурс Экспертного Сообщества - речевая деятельность, участники которой объединены профессиональными целями, формирующими единый горизонт интерпретации понятия, и владеют экспертным знанием, с опорой на которое выстраивают свою коммуникацию. 
Дискурс Различий - не абсолютное противоречие и глобальное отсутствие понимания. Это «начало движения к всеобщему» [6. С. 117]. Дискурсу Различий не свойственны хаос взглядов и отсутствие рационального ядра. Субъекты понимают главную суть, но отрицают точки зрения своих оппонентов, оперируя концептами как феноменологическими сущностями, основанными на индивидуальном опыте. Приведем пример высказываний присяжных заседателей, характеризующих характер вины подсудимой:

Присяжный 1: В данном случае я сначала с душой подошел $к$ этой девушке. Но затем я сделал вывод, что она виновата.

Присяжный 2: Если бы она была хорошим и честным, она бы на это не пошла (Телешоу «Суд присяжных»).

Присяжный 1 с помощью фразеологизма определяет свое отношение к степени вины подсудимой. Данный фразеологический оборот имеет в рассматриваемом контексте размытые семантические границы в силу неограниченности объема. Присяжный 2 характеризует подсудимую также с опорой на феноменологические знаки хороший и честный. Наблюдаются расхождения в суждениях и оценках правового поведения подсудимой, исходя из различий в опыте переживания, мнения, оценки тех или иных аспектов правомерного поведения, образующих у каждого свой уникальный дискурс.

В пределах Дискурса Различий индивид, не владеющий экспертным знанием, предстает как личность, обладающая мнениями, базирующимися на субъективном восприятии мира и ранее полученном опыте. Феноменологическое значение представляется как индивидуальная интерпретация знаков, которая зиждется на личном опыте интеракции индивида с данными семиотическими сущностями [8. С. 116]. Примером феноменологической интерпретации знака является и следующий фрагмент дискурса присяжных заседателей при вынесении вердикта:

Присяжный 1: Мотивы для совершения данного преступления могли быть у нескольких человек. Нет прямых улик в совершении данного преступления.

Присяжный 2: Я хочу возразить. Есть же показания свидетелей. Как раз прямые улики указывают на то, что она именно убила.

Присяжный 3: Прямые улики - это у нас нож, отпечатки пальцев на орудии убийства (Телешоу «Суд присяжных»).

В силу отсутствия экспертных знаний присяжные интерпретируют юридическое понятие «прямые улики», исходя из личного опыта. Присяжный 2 прямыми уликами называет представленные стороной обвинения косвенные доказательства, относя к ним показания свидетелей, которые участниками юридического экспертного сообщества относятся к косвенным - обстоятельствам, дающим основания для определенных выводов о данных обстоятельствах. Присяжный определяет прямые доказательства путем перечисления их разновидностей, но оставляя данный знак без дефиниции по причине отсутствия экспертного знания в области уголовно-процессуального права. При- 
сяжные заседатели обладают различным опытом, а следовательно, и интерпретация одних и тех же явлений у них не совпадает, «общего языка в Дискурсе Различий не бывает» [6. С. 10].

Приведем еще один пример.

Присяжный: Николаев лишился своей должности за махинации. Если бы он был хорошим и честным, он бы на это не пошел. У его подельника были явно налажень потоки, куда можно деть краденое (Телешоу «Суд присяжных»).

Пример иллюстрирует, что субъект речи описывает уголовно-правовую ситуацию, используя знаки (махинация, честный, подельник, деть краденое), для которых характерно отсутствие однозначной семантики, предполагающие множественную интерпретацию в зависимости от индивидуального опыта интерпретатора. Основой феноменологического восприятия субъекта речи являются концепты «честность» / «нечестность», «махинация», которые характеризуются неопределенно большим объемом. Так, к примеру, среди признаков концепта «махинация» можно выделить следующие: «нечестные действия», «жульничество», «тихая операция без свидетелей», «хитрый замысел» и др. В уголовно-правовом дискурсе участника экспертного юридического сообщества данные понятия вербализовались бы иным образом: махинация - мошенничество, подельник - соучастник, деть краденое - реализовать похищенное имущество. Данным знакам в юридическом сообществе присуща единая интерпретанта, не зависящая от контекста и феноменологического опыта интерпретатора.

Далее отметим, что Дискурс Различий возможен не только с участием носителей обыденного языкового сознания, но и экспертов, когда они организуют его вокруг знаков, не имеющих четких дефиниций. Приведем пример спора между участниками юридического экспертного сообщества по поводу значения знака «опасный».

Адвокат: На данной записи мы видим свидетеля Зиброву, которая наносит опасный удар по голове погибшего.

Прокурор: Я возражаю против формулировки «опасный». Мы не знаем, какой он был.

Адвокат: По голове все опасно палкой (Телешоу «Суд присяжных»).

Участники коммуникации понимают главную суть, но отрицают точку зрения своего оппонента, оперируя концептом как феноменологической семиотической сущностью. Разногласия у адвоката и прокурора вызывает семантика прилагательного «опасный». Поскольку в уголовном праве отсутствует определение понятий «опасный», «опасный удар», коммуниканты обращаются к индивидуальному опыту, различия в котором и приводят к полемике. Следует отметить, что обращение экспертов к знакам с множественной интерпретантой может быть проявлением манипулятивного воздействия. В судебном заседании с участием присяжных заседателей подобные знаки обладают манипулятивным потенциалом и их намеренное использование по- 
могает склонить присяжных заседателей на свою сторону, поскольку позволяет соотнести с той интерпретантой, которая соответствует выбранной линии защиты или обвинения.

Таким образом, множественность, вариативность интерпретаций действительности в Дискурсе Различий создает ситуации для конструирования особой реальности, когда представление и восприятие какого-либо фрагмента действительности неотделимы от оценочного отношения к нему.

Следующая форма социального взаимодействия - Дискурс Согласования - организуется вокруг понятия, содержание которого представляет собой совокупность признаков, принятых в результате общественной конвенции [7. С. 17], что помогает прийти к консенсусу и согласовать различные взгляды. Так, если знак «корысть» в Дискурсе Различий имел множество признаков, среди которых страсть к наживе, материальная выгода, материальная заинтересованность, падкость на барыш, жадность к деньгам и т.П., лишившись оценочных признаков в Дискурсе Согласования, он приобрел ряд неизменных признаков, которые отличают от смежных уголовных деяний: получение материальной выгоды для виновного или других лич или избавление от материальных затрат [9].

Примером Дискурса Согласования является общение адвоката и клиента. Адвокат воспринимает клиента как субъекта, находящегося за пределами экспертного сообщества, не обладающего экспертным знанием, не владеющего специальной терминологией и не способного ее правильно интерпретировать. Чтобы выйти на продуктивный диалог, адвокат вынужден отказываться от профессионального языка и продуцировать Дискурс Согласования, центром которого являются понятия, которые конструируются для того, чтобы иметь общий язык при обсуждении проблем, опираясь на логические соображения [10. С. 5]. Профессиональное предназначение адвоката требует Дискурса Согласования, поэтому вырабатывается общий контекст интерпретации, а у клиента формируется адекватная интерпретанта, несмотря на отсутствие экспертного знания. Таким образом, в процессе общения с клиентом адвокат сталкивается с необходимостью, во-первых, закодировать информацию, подлежащую передаче клиенту в понятных для него знаках, которые он способен расшифровать; во-вторых, он должен обеспечить передачу «кода» по каналу коммуникации; в-третьих, он должен помочь клиенту осуществить раскодирование информации и обеспечить понимание и верную интерпретацию сказанного. Коммуникативная неудача наступает, если участник экспертного сообщества использует «закодированный» язык, не желая давать оппоненту, не обладающему экспертным знанием, ключ к расшифровке.

Приведем пример диалога адвоката и истца.

Адвокат: Мировое соглашение возможно?

Истец: В каком смысле?

Адвокат: Вы согласны пойти на уступки?

Истеці: Раз другого выхода нет, я согласен (Телешоу «Час суда»).

В данном примере адвокат поясняет устоявшийся в гражданскопроцессуальном производстве термин «мировое соглашение», значение кото- 
рого может быть незнакомо клиенту, уточняя его главный признак - взаимные уступки. Вторая ответная реплика истца доказывает, что клиент верно раскодировал вопрос адвоката, т.е. коммуникация оказалась эффективной в результате перехода от термина к понятию.

Поскольку профессиональное предназначение адвоката, судьи, прокурора и других юристов требует Дискурса Согласования, необходимо постоянное взаимодействие коммуникантов с целью выработки общего контекста интерпретации. Это позволяет сформировать у адресата адекватную интерпретацию описываемого объекта или явления, независимо от знаний в области права. Рассмотрим еще один пример.

Судья: Поскольку вы получили эти деньги под обязательства неисполненные, эта сделка считается ничтожной, недействительной. Поэтому вы должны вернуть 250 тысяч Илье Олеговичу (Телешоу «Час суда»).

Судья как участник экспертного сообщества осознает отсутствие знаний гражданского законодательства у истца и ответчика, поэтому наряду с дескрипцией ничтожная для характеристики сделки, не отвечающей обязательным требованиям закона, употребляет поясняющий знак недействительная, который может быть верно интерпретирован и за пределами экспертного сообщества. Построение Дискурса Согласования в процессе коммуникации с истцом и ответчиком позволяет судье достичь коммуникативного эффекта.

Таким образом, согласование может быть достигнуто, если оба коммунканта одинаково адекватно интерпретируют используемые в процессе коммуникации понятия. Для этого эксперт вынужден отказываться от специальной терминологии и инициировать Дискурс Согласования, основной единицей которого является понятие. Рассмотрим еще один пример, интересный с точки зрения возможности перехода от одной формы социального взаимодействия к другой.

Свидетель: Мы бы его сразу вывели на чистую воду, этого брачного афериста.

Адвокат: Почему вы Аморова называете брачным аферистом, откуда такой термин возник? Нет такого официального термина.

Судья: Какие официальные термины? Мы допрашиваем свидетеля, который изъясняется понятным русским языком (Телешоу «Час суда»).

Свидетель, не обладая экспертными знаниями в области уголовного права, характеризует подсудимого с помощью знака «брачный аферист». Адвокат пытается вовлечь оппонента в свой экспертный дискурс и предлагает отказаться от использования концептуальных знаков, однако судья напоминает о необходимости конструирования Дискурса Согласования, поскольку одним из коммуникантов является лицо, не являющееся участником юридического экспертного сообщества.

Итак, Дискурс Согласования есть сфера оперирования понятиями, базирующимися на естественно-рассудочном знании, поскольку все коммуникан- 
ты едины во мнении. Их интенциональный горизонт и интерпретация семиотических сущностей сходятся в одной точке [8. С. 41].

И наконец, последняя форма социального взаимодействия коммуникантов в рамках юридических дискурсивных практик - Дискурс Экспертного Сообщества, субъектами которого выступают исключительно лица, обладающие профессиональными знаниями и владеющие специальной терминологией.

Поскольку объектом нашего исследования является юридический дискурс, отметим характерную особенность юридического экспертного сообщества. Здесь следует сказать, что экспертное сообщество юристов клеймят, наверное, больше чем какое-либо другое. К примеру, в английском языке можно насчитать около десятка негативных обозначений представителей данной профессии: shyster, pettifogger, ambulance chaser, mouthpiece, shark, hired gun; в испанском языке юристов пренебрежительно называют buscapleitos, leguleyo, picapleitos, tinterillo, abogado firmyn; во французском avocassier, chicaneur, avocat marron и т.п. Об отсутствии четкости в формулировках говорил и Томас Мор в своем произведении «Утопия», описывая идеальный мир без юристов [11]. Д. Меллинкофф полагает, что причина враждебности по отношению к членам юридического сообщества заключается в их умышленном запутывании вопросов, использовании «мертвого» языка, «кишащего неопределенностью» [12. Р. 122].

Языковые традиции юридического сообщества - это своего рода знак, символизирующий участие в нем, принадлежность к юридической профессии. Профессиональный язык выполняет важную роль в символическом пространстве институционального дискурса. Юридический язык в этом плане является наиболее репрезентативным. Как пишет уже упомянутый Д. Меллинкофф, «самый лучший способ сохранить монополию на профессию - запереть свои профессиональные секреты в сейфе неизвестного языка» [Ibidem].

Через закрепление в определенной институциональной роли эксперт становится носителем «надындивидуальной функции, которую он выполняет в сообществе, порождает дискурс, опираясь на «набор конструктивных стратегий, находящихся под социальным и идеологическим контролем» [13. С. 150]. Рассмотрим фрагмент дискурса допроса свидетеля.

Свидетель: Мне он показался нормальным человеком.

Прокурор: То есть вменяемым?

Адвокат: Через нотариуса оформляли сделку? Нотариус проверял дееспособность гражданина? (Телешоу «Суд присяжных»).

Свидетель, не имея знаний специальной юридической терминологии и опираясь на собственный феноменологический опыт и знания, характеризует психическое состояние подсудимого с помощью дескрипции «нормальный» концепта с размытой семантикой. Прокурор и адвокат привыкли оперировать знаками, исключающими множественность интерпретаций, поэтому в уточняющих вопросах они обращаются к принятым в юридическом экспертном сообществе терминам «вменяемость» и «дееспособность» с четко очерчен- 
ными семантическими границами, имеющим закрепленные дефиниции. Различия в интерпретации данных знаков сведены к нулю в силу присущей им плотности содержания и ограниченности объема. Используемые коммуникантами термины отражают профессиональные интересы и предпочтения. Единая интерпретанта, которой обладают знаки вменяемость и дееспособность, позволяет участникам коммуникации уйти в Дискурс Различий. Взаимодействуя в узких рамках Дискурса Экспертного Сообщества, используя исключительно профессиональную терминологию, коммуниканты экономят время, обозначая понятия принятыми в профессиональной среде терминами, что позволяет общаться более эффективно.

Таким образом, участники Дискурса Экспертного Сообщества в отличие от носителей обыденного сознания стремятся к максимальной однозначности понятия. И если последним присущи субъективная интерпретация, мягкая семантизация и приблизительное отождествление, постмодернистское представление о множественности интерпретации как основном способе бытия истины, то участнику Дискурса Экспертного Сообщества близка «аристотелевская формальная логика» [14. С. 27]. Ситуация непонимания здесь возникает редко, а если это происходит, то она быстро разрешается, поскольку термин определен единым для коммуникантов набором свойств.

Итак, мы рассмотрели три формы социального взаимодействия в рамках юридических дискурсивных практик (Дискурс Различий, Дискурс Согласования и Дискурс Экспертного Сообщества), характер которых определяется уровнем владения экспертным знанием и коммуникативными интенциями субъектов речи. Дискурс Различий субъекты формируют в силу отсутствия экспертного знания или необходимости оказания манипулятивного воздействия, поскольку знаки, вокруг которых он выстраивается, позволяют дать аксиологическую оценку, предполагают множественность интерпретаций. Дискурс Согласования помогает прийти к консенсусу и согласовать различные взгляды. В правовой коммуникации его формируют эксперты в общении с носителями обыденного сознания, не обладающими экспертным знанием, чтобы выйти на продуктивный диалог. В Дискурс Экспертного Сообщества вступают носители экспертного знания, которые, овладев силой термина, продуцируют высказывания, подчиняясь определенным конвенциям и правилам.

\section{Лumepamypa}

1. Козырев Г.И. Социальное действие, взаимодействие, поведение и социальный контроль // Социологические исследования. 2005. № 8. С. 124-129.

2. Филлипс Л., Йоргенсен М.В. Дискурс-анализ: Теория и метод. Харьков: Гуманитарный Центр, 2004. $336 \mathrm{c}$.

3. Иманжусупова С.У. Дискурс как основа социального взаимодействия // Молодой ученый. 2012. № 6. С. 252-255.

4. Шейгал Е.И. Семиотика политического дискурса. М.: ГноЗИС, 2004. 325 с.

5. Крапивкина O.A. Субъект в условиях юридического дискурса: лингвопрагматический анализ. Иркутск: ИРНИТУ, 2015. 153 с.

6. Каплуненко А.М. Концепт - Понятие - Термин: эволюция семиотических сущностей в контексте дискурсивной практики // Азиатско-Тихоокеанский регион: диалог языков и культур. Иркутск, 2007. С. 115-120. 
7. Каплуненко A.M. Federal / Federalism: от концепта к понятию и термину // Вестн. Иркут. гос. лингв. ун-та. 2012. № 2(18). С. 16-21.

8. Тюрнева T.B. Опыт анализа лингвосемиотического контекста EDUCATION: концепт, понятие, термин: на материале английского языка: дис. ... канд. филол. наук. Иркутск, 2012. 202 с.

9. Постановление Пленума Верховного суда Российской Федерации от 29 января 1999 г. URL: Consultant.ru

10. Демьянков В.3. Когниция и понимание текста // Вопр. когнитивной лингвистики. Москва; Тамбов, 2005. № 3. С. 5-10.

11. Мор T. Утопия / пер. с лат. Ю.М. Каган. М.: Наука, 1978. 412 с.

12. Mellinkoff D. The Language of the Law. Boston: Resource Publications, 2004. $526 \mathrm{p}$.

13. Dijk van T. Discourse and Context: A sociocognitive approach. Cambridge: Cambridge University Press, 2008. 288 p.

14. Голев Н.Д. Правовая коммуникация в зеркале естественного языка // Юрислингвистика-7: Язык как феномен правовой коммуникации. Барнаул, 2006. С. 8-36.

\section{Источники примеров}

1. Час суда. URL: http://www.chassuda.ru/

2. Суд присяжных. URL: http://sudprisyazhnyh.ucoz.ru/

\section{ANALYSIS OF DISCOURSES AS FORMS OF SOCIAL INTERACTION (A CASE-STUDY OF COURT SHOWS)}

Vestnik Tomskogo gosudarstvennogo universiteta. Filologiya - Tomsk State University Journal of Philology. 2017. 46. 21-30. DOI: 10.17223/19986645/46/2

Olga A. Krapivkina, Irkutsk National Research Technical University (Irkutsk, Russian Federation). E-mail:koa1504@mail.ru

Keywords: discourse, legal discourse, social interaction, expert community, term, notion.

The paper describes discourse as a tool of social interaction. The purpose of the research is to study the forms of social interaction in legal discourse practices. The paper is a case study of court shows aired on Russian and American TV channels. Three forms of social interactions in legal settings are analysed: Discourse of Differences, Discourse of Concord, and Discourse of Expert Community. The choice of the form of social interaction depends on communicative intentions, purposes and characteristics of discourse opponents (degree of expert knowledge). The paper is based on the theory of semiotic entities evolution suggested by A.M. Kaplunenko. The author assumes that every action is an interaction as it is made for certain intentions and purposes. The subjects of social interaction are guided by mutual expectations based on the social roles of each other and existing institutional standards of behaviour. The paper says that social interaction is not possible beyond discourse practices. Any type of interaction suggests communication through discourse. Discourse as a socially arranged, regulated set of communicative acts manifesting itself in texts is a tool of social interaction. By generating discourses in different social situations, communicators construe specific social roles and identities. The examples analysed show that communicators produce their institutional discourses around different semiotic entities depending on communicative purposes and degree of their own expertise and their opponents' expertise. Only taking into account the characteristics of the discourse opponent, one can achieve a specific perlocutionary effect. For example, while communicating with each other experts usually use special terminology, in communication with non-experts they abandon their professional language requiring a code to decipher it, which their opponents lack, and use notions which are based on natural rational knowledge. The paper concludes that the speaking subject performing one and the same social role can choose different forms of social interaction to achieve a specific communicative effect. Being in a specific communicative situation, the subject evaluates it and chooses a relevant communicative action following the rules and norms developed by the discourse community. The paper is of practical value as it can help lawyers produce their discourse with clients based on those semiotic entities which enable the perlocutionary effect.

\section{References}

1. Kozyrev, G.I. (2005) Sotsial'noe deystvie, vzaimodeystvie, povedenie i sotsial'nyy kontrol' 
[Social action, interaction, behavior and social control]. Sotsiologicheskie issledovaniya - Sociological Studies. 8. pp. 124-129.

2. Fillips, L. \& Yorgensen, M.V. (2004) Diskurs-analiz. Teoriya i metod [Discourse analysis. Theory and method]. Translated from English. Kharkov: Izd-vo Gumanitarnyy Tsentr.

3. Imanzhusupova, S.U. (2012) Diskurs kak osnova sotsial'nogo vzaimodeystviya [Discourse as the basis of social interaction]. Molodoy uchenyy. 6. pp. 252-255.

4. Sheygal, E.I. (2004) Semiotika politicheskogo diskursa [The semiotics of political discourse]. Moscow: GnoZIS.

5. Krapivkina, O.A. (2015) Sub"ekt v usloviyakh yuridicheskogo diskursa: lingvopragmaticheskiy analiz [Subject in terms of legal discourse: linguopragmatic analysis]. Irkutsk: IRNITU.

6. Kaplunenko, A.M. (2007) [Concept-Notion-Term: evolution of semiotic entities in the context of discursive practice]. Aziatsko-Tikhookeanskiy region: dialog yazykov i kul tur [Asia-Pacific Region: dialogue of languages and cultures]. Proceedings of the international conference. Irkutsk: Irkutsk State Linguistic University. pp. 115-120. (In Russian)

7. Kaplunenko, A.M. (2012) From the concept to the term: semiotic evolution of the nomination 'Federal / Federalism'. Vestnik Irkutskogo gosudarstvennogo lingvisticheskogo universiteta - Bulletin of Irkutsk State Linguistic University. 2(18). pp. 16-21. (In Russian)

8. Tyurneva, T.V. (2012) Opyt analiza lingvosemioticheskogo konteksta EDUCATION: kontsept, ponyatie, termin: na materiale angliyskogo yazyka [Experience of analysis of the linguistic and semiotic context EDUCATION: concept, notion, term: on the material of the English language]. Philology Cand. Diss. Irkutsk.

9. Supreme Court of the Russian Federation. (1999) Resolution of the Plenum of the Supreme Court of the Russian Federation of January 29, 1999. [Online] Available from: http:www.consultant.ru. (In Russian)

10. Dem'yankov, V.Z. (2005) Kognitsiya i ponimanie teksta [Cognition and understanding of the text]. Voprosy kognitivnoy lingvistiki. 3. pp. 5-10.

11. More, T. (1978) Utopiya [Utopia]. Translated from Latin by Yu.M. Kagan. Moscow: Nauka.

12. Mellinkoff, D. (2004) The Language of the Law. Boston: Resource Publications.

13. Dijk, T.A. van. (2008) Discourse and Context. A sociocognitive approach. Cambridge: Cambridge University Press.

14. Golev, N.D. (2006) Pravovaya kommunikatsiya v zerkale estestvennogo yazyka [Legal communication in the mirror of natural language]. In: Golev, N.D. (ed.) Yurislingvistika-7: Yazyk kak fenomen pravovoy kommunikatsii [Yurislingvistika-7: Language as a phenomenon of legal communication]. Barnaul: Altai State University.

\section{Sources of Examples}

1. Chas suda [The hour of trial]. [Online] Available from: http://www.chassuda.ru/.

2. Sud prisyazhnykh [The jury trial]. [Online] Available from: http://sudprisyazhnyh.ucoz.ru/. 